\title{
ROLE OF CHITOSAN, CARBOXY METHYL CELLULOS, POLYVINYL PYRROLIDONE, KYRON T 134 AND PRIMOGEL TO DESIGN THE MOUTH DISINTEGRATING TELMISARTAN TABLET WITH EXTENDED RELEASE PROFILE
}

Muhammad Abdullah Akram ${ }^{1}$, Taha Nazir ${ }^{1,2,3^{*}}$, Saeed Ur Rasheed Nazir ${ }^{1}$, Nida Taha ${ }^{3}$

1.Faculty of Pharmacy, University of Sargodha, Sargodha 40100 Pakistan 2.Biochemistry, Chemical Pathology, Molecular Biology Research Group, UMC\&RC, University of Sargodha, Sargodha 40100 Pakistan 3.ICDTD Inc., 913

Northumberland Ave Saskatoon SK Canada.

Submitted: $14-01-2017$

Revised: 20-03-2011

Accepted: 11-04-2017

*Corresponding author Taha Nazir

Email:

taha.nazir@uos.edu.pk

\begin{abstract}
The Mouth Disintegrating Extended Release Telmisartan (MDERT) tablets are designed for adequate pharmacokinetic profile to avoid the unusual peaks and troughs. Although, there are extensive advance techniques used to deliver drugs. But oral route is still remains effective in most of the therapeutical situations. Thus we aimed this study to formulate a dosage form with dual character of orodispersion as well as extended effectiveness. MDERTS dosage form was prepared by direct compression method. The major components of this preparation were Telmisartan (TLM), Carboxy methyl cellulose polyvinyl Pyrrolidone, Chitosan, Talc, Mg-stearate, Lactose. The MDERTS dosage form was characterized with different determinants. While, the drug release curves of all 6 formulations upto $12 \mathrm{~h}$, DSC spectra of TLM, Kyron $\mathrm{T}_{134}$, Primogel, TLM+Kyron $\mathrm{T}_{134}$ +Primogel, Chitosan, CMC and different excepients are presented as comprehensive scientific figures. DSC and FTIR spectroscopic studies indicate the compatibility of drugs with each other and with excipients. Moreover, the formulation F2 containing more than $10 \%$ of Kyron $\mathrm{T}$ had shown best results. Whereas, the overall results had shown that Kyron $\mathrm{T}$ containing tablets had best, in vitro dispersion time, wetting time and wetting volume, water absorption ratio. The order in which superdisintegrants and polymers had produced desirable effect is Kyron T134 > Kyron T134134 + primogel > primogel and for polymers chitosan> chitosan+CMC> chitosan +PVP> CMC> CMC+PVP> PVP. Thus, Kyron $T$ is the best superdisintegrant of others which were used in present study and direct compression method is the best used to prepare extended release mouth disintegrating tablets.
\end{abstract}

Key words: Chitosan, CMC, PVP, Kyron T 134 , Primogel TLM, MDERT's

\section{INTRODUCTION}

Orally disintegrating Telmisartan (TLM) tablet with extended release profile is intended to assure the drug compliance with minimal adverse effects. The Mouth Disintegrating Extended Release Telmisartan (MDERT) tablets are designed for sustained therapeutic benefits along with adequate pharmacokinetic profile to avoid the unusual peaks and troughs (Allen and Remington, 2012)

Moreover, the chitosan is carbohydrate and its source is skeleton of shellfish, also some other sources may includes shrimp and crab, used in different pharmaceutical preparations, act as cationic natural polysaccharides have diverted considerable attention to its diverse applications as renewable nontoxic bio degradable polymer. (Ravi et al., 2004) Polyvinyl Pyrrolid one (PVP), also commonly called povidone, is a polymer and its polymeric units are N-vinylpyrrolidone. Polyvinyl Pyrrolidone is used in different pharmaceutical industries as PV-expander (plasma volume expander) for patients with trauma. The most widely used oldest disintegrant, the starch is provided with a dramatic disintegrating properties and are available as Explotab $\AA$ and Primogel.(Ieva et al., 2009)

It is chemically cross-linked and carboxymethylated potato starch. It is 
manufactured by cross-linking starch with sodium trimetaphosphate followed by carboxymethylation with sodium monochloroacetate. Approximately one glucose monomer unit in every four is substituted. (Shanmugam, 2015)

Whereas, the Kyron -T134 is basically derivative of polymer- polyacrylic acid in cross linking form used for taste masking and stabilization of drug in different pharmaceutical industries. It is whitish in color and swells upon contact with water. Different vitamins may deteriorate on storage e.g vitamin B12, so their stabilization demands Kyron $-\mathrm{T}_{134}$.

Although, there are extensive advance techniques used to deliver drugs. But oral route is still remains effective in most of the therapeutical situations. Oral dosage forms also having problems in swallowing because more than $35 \%$ of population is arrested in such problem and such problem is associated with many pathological problems like. (Belal et al., 2014) Thus, Mouth Disintegrating TLM (MDT's) Tablet with Extended Release Profile can be recommended for parkinsonism, motion sickness, senseless patient, patients with old age, mentally disabled persons, unavailability of water and children. The superdisintegrants and polymers were compressed directly to produce the MDT's. The main objectives of this study were to formulate an antihypertensive extended release MDT's with dual character of orodispersion as well as extended effectiveness. The active superdisintegrants and polymers may have desired pharmaceutical characteristics, suitable in challenging environment during travelling or situations of unavailability of water. Hence, we have formulated MDT's that having mechanical strength in prescribed range. That can be manufactured expediently with existing conventional machinery. The formulation is target cost-effective and has constant and uniform outcomes.

Hence, the pharmacy professionals are still working to formulate an ideal ODT's with sustained therapeutic effect for many hours. That may potentially minimize the irregular fluctuations in plasma that may effects the required therapeutic outcomes. Therefore, MDERTs have dual benefits of immediate as well as sustained therapeutic effect. MDERT's also have comparatively lower dose, frequency and adverse effects with better economical benefits. (Bankars et al., 2014)

\section{MATERIAL AND METHODS}

This research study was conducted in Hitech Lab., and Department of Pharmaceutics, Faculty of pharmacy, University of Sargodha, Pakistan during June, 2014 to February, 2015. The major equipments used were included FTIR (IR Prestige 21 Shimadzu), Thermal Analyzer (SDT Q600), Oven (IM-30 IRMECO Gmb), Spectrophotometer UV 1700 (Shimadzu), Micropipettes, pH meter (Jenway 3510), Friabilator (Pharma test, Germany), Weight balance (Shimadzu A x200), Dissolution Apparatus (Pharma test) and Disintegration Apparatus (Pharma test). whereas the major materials used during experimental work were T134134 (Qantar Pharmaceuticals), TLM (Highnoon Laboratories), Carboxy Methyl Cellulose (Vision Laboratories), Mg-stearate and talc were (Willson Pharmaceuticals, Lactose (Welcare Pharmaceutical), Chitosan (Highnoon Laboratories), Primogel (Bosch Pharmaceuticals), Polyvinyl Pyrrolidone (S.B pharmaceuticals), Saccharine sodium and flavors (Saffron Pharmaceuticals).

\section{Direct compression method}

All the desired materials such as drug, polymers, superdisintegrants and other excipients required for extended release orodispersible tablets were weighed accurately on scientific electronic weighing balance (Table I).

The two portions of all six formulations were designed as extended release and orodispersible. The materials were weighed on electrical balance and then passed through sieve No 40. These were homogenized in tumbling cylindrical mixer for 10 minutes at a speed of $15 \mathrm{rpm}$. Then a wet mass of this mixture was prepared by adding a suitable amount of water to produce granules. Granules were dried at the temperature of $60^{\circ} \mathrm{C}$ over the night. Then granules were brought so that to be passed through a sieve of mesh No.80 to receive granules of desired size. At the end we mixed both portions of weighing materials for 06 
Table I. Formulations of mouth disintegrating and extended release portions of formulations.

\begin{tabular}{|c|c|c|c|c|c|c|}
\hline \multicolumn{7}{|c|}{ Mouth disintegrating portion of formulation } \\
\hline Ingredients (mg) & F1 & F2 & F3 & F4 & F5 & F6 \\
\hline TLM & 40 & 40 & 40 & 40 & 40 & 40 \\
\hline Pre-gelatinize Starch & 16 & - & 12 & 08 & 04 & - \\
\hline Kyron T134 & - & 16 & 04 & 08 & 12 & - \\
\hline Mg-Stearate & 04 & 04 & 04 & 04 & 04 & 04 \\
\hline Talc & 04 & 04 & 04 & 04 & 04 & 04 \\
\hline Lactose & 77 & 77 & 77 & 77 & 77 & 93 \\
\hline Orange Flavor & 05 & 05 & 05 & 05 & 05 & 05 \\
\hline Saccharine Sodium & 04 & 04 & 04 & 04 & 04 & 04 \\
\hline $\begin{array}{r}\text { Total Weight(mg) } \\
\end{array}$ & 150 & 150 & 150 & 150 & 150 & 150 \\
\hline \multicolumn{7}{|c|}{ Extended release portion of formulation. } \\
\hline TLM & 40 & 40 & 40 & 40 & 40 & 40 \\
\hline $\mathrm{CMC}$ & 20 & - & - & 20 & 20 & - \\
\hline Chitosan & - & 20 & - & 20 & 20 & 20 \\
\hline PVP & - & - & 20 & - & -20 & \\
\hline Mg-Stearate & 04 & 04 & 04 & 04 & 04 & 04 \\
\hline Talc & 04 & 04 & 04 & 04 & 04 & 04 \\
\hline Lactose & 82 & 82 & 82 & 82 & 82 & 82 \\
\hline Total Weight(mg) & 150 & 150 & 150 & 150 & 150 & 150 \\
\hline
\end{tabular}

formulations to homogenize in tumbling cylindrical mixer for $20 \mathrm{~min}$ and compressed into extended release orodispersible tablets by using ZP 19 station rotary tablet compressing machine. (Ieva et al., 2009)

\section{Pre and post compression Determinants}

The flow properties were investigated by measuring the bulk and tapped density. Other pre-compression determinants were Bulk density, tapped density, angle of repose aor, carr's compressibility index, and hausner's ratio. While the post-compression determinants were thickness, weight variation, hardness and friability, wetting time, water absorption ratio, drug content, in vitro drug release, and in vitro disintegration time.

\section{Study Design}

MDERTS dosage form was prepared with ambition of to get dual effects; producing immediate as well as sustain therapeutic effect. Direct compression method used for it. The major components of this preparation were TLM, Carboxy methyl cellulose polyvinyl Pyrrolidone, Chitosan, Talc, Mg-stearate, Lactose. While the equipments and instruments used to study the parameters were FTIR (IR Prestige 21 Shimadzu), Thermal Analyzer (SDT Q600), Oven (IM-30 IRMECO Gmb), Spectrophotometer UV 1700 (Shimadzu), Micropipettes, pH meter (Jenway 3510), Friabilator (Pharma test, Germany), Weight balance (Shimadzu A x200), Weight balance (Shimadzu A x200), Disintegration Apparatus (Pharma test), Aluminum foil, Platinum loop, Spatula, Beakers. Finally, we have characterized the MDERTS dosage form with different determinants- Bulk density, Tapped density, Angle of repose, Carrs index, Hausners ratio, Thickness, Weight variation, Hardness, Weight variation, Wetting time, Wetting volume, Water absorption ratio, Drug content, In vitro drug release, In vitro disintegration time etc. The final results of Angle of Repose, Bulk density, Tapped density, Hausner's Ratio and Carr's Index, Hardness, Weight variation, Thickness, Friability, Disintegration time and Wetting time has been tabulated to illustrate the finding. While, the drug release curves of all 6 formulations upto $12 \mathrm{~h}$, DSC spectra of TLM, Kyron $\mathrm{T}_{134}$, Primogel, TLM+Kyron $\mathrm{T}_{134}+$ Primogel, Chitosan, CMC and different 
excepients are presented as comprehensive scientific figures.

\section{Formulations Criteria}

The factors that determine the best formulation were the disintegration time, invitro dispersion time, wetting time of finished dosage form, wetting volume of preparation, water absorption ratio, drug release curve or cumulative \%age drug release, performance of superdisintegrants for better disintegration properties, water absorption ratio for tablets depends upon the method of preparation and concentration of superdisintegrants, nature of excipients and method of tablets preparation and tablet strength that determine the dissolution

\section{Statistical Analysis}

The computer software SPSS used for statistical ANOVA (Analysis of Variance) analysis. That is applied to design, develop and formulate be best possible mouth disintegrating TLM tablet with extended release profile using response surface methodology.

\section{RESULT AND DISCUSSION}

Powder blend was prepared for 06 formulations by using different concentrations of sustained release edible polymers and superdisintegrants. These formulations were characterized for rheological properties such as; Carr's Index, Hausner's Ratio Angle of Repose, Tapped Density and Bulk Density. Bulk density and tapped density of 06 formulations was found in the range of 0.613 to $0.627 \mathrm{~g} / \mathrm{mL}$ and 0.721 to $0.749 \mathrm{~g} / \mathrm{mL}$ respectively. Angle of Repose of 06 formulations was noted to be in the range of 21.6 to $24.5(\Theta)$. Hausners Ratio of 06 formulations was noted to be in the range of 1.16 to $1.20 \%$. Carr's Index of 06 formulations was found in the range of 17.55 to $19.50 \%$.These results of powder blend are well within specified limits (Table II).

This powder blend was used to make Extended release ODTs of TLM by as discussed. These tablets were evaluated for different parameters recommended for extended release MDTs. The results of hardness, weight variation, thickness and friability are present within the pharmacopeial limits ( Table III, IV).

\section{Table Fourier Transform Infrared (FTIR) spectroscopy}

Fourier transform infrared spectroscopy can be used to analyze the individual pure expedients (Bankars et al., 2014) and in combination (formation). The FTIR spectra of TLM alone and in combination with superdisintegrants and polymers were taken to check any interaction between drug molecules as well as with superdisintegrants (Figure 1). The spectrum of FTIR had shown that there was complete presence of characteristic peaks of drug molecules and excipients. It means that there was no interaction between and drug excipients.

The FTIR spectrum of pure TLM showed the prominent peak of the drug at $3400 \mathrm{~cm}^{-1}$ of $\mathrm{O}-\mathrm{H}$ stretching of $-\mathrm{COOH}$ acid and other peaks at $2960 \mathrm{~cm}^{-1}$ due to $\mathrm{C}-\mathrm{H}$ stretching vibration of aromatic group, $-\mathrm{OH}$ bending and $-\mathrm{C}=\mathrm{O}$ stretching of $-\mathrm{COOH}$ acid at $1385 \mathrm{~cm}^{-1}, \mathrm{C}=\mathrm{C}$ stretching of aromatic group at $1600 \mathrm{~cm}^{-1}$ and functional group of $(-\mathrm{COOH})$ at $1697 \mathrm{~cm}^{-1}$ (Figure 2). FTIR spectra of TLM with excipients and excipients with each other also shown that same characteristic peak were present as single spectra of drug and excipients (Figure 3).

Our formulations contain Kyron $\mathrm{T}_{134}$ and primogel in combination in different ratios. The release data of all 06 formulations had also shown that chitosan has best retarding properties than PVP and CMC. The order in which superdisintegrants and polymers had produced desireable effect is shown as under Kyron $\mathrm{T}_{134}>$ Kyron $\mathrm{T}_{134}+$ primogel $>$ primogel and for polymers chitosan $>$ chitosan $+\mathrm{CMC}>$ chitosan+PVP $>\mathrm{CMC}>\mathrm{CMC}+\mathrm{PVP}>\mathrm{PVP}$.

Our findings are in line with Lepek et al., (2013), who reported TLM (TLM) as a poor water-soluble angiotensin II receptor antagonist in crystalline form. That was transformed into the amorphous state by the melt quench technique, as well as a cryogenic grinding method, in order to improve its physiochemical properties. The chemical stability of TLM, that is, the tendency of the material to resist change or decomposition due to internal reaction, or due to the effects of air, heat, light, pressure, etc., during formation of the amorphous phase was assessed by monitoring high performance liquid chromatography. Measurements of the 
Table II. Results of Hardness, Weight variation, Thickness, Friability, Disintegration time and Wetting time

\begin{tabular}{ccccccc}
\hline & \multicolumn{5}{c}{ Parameters } \\
\cline { 2 - 7 } Code & $\begin{array}{c}\text { Wt. Variation } \\
\text { (mg) }\end{array}$ & $\begin{array}{c}\text { Hardness } \\
\mathbf{K g} / \mathbf{c m}^{\mathbf{2}}\end{array}$ & $\begin{array}{c}\text { Thickness } \\
\mathbf{( m m})\end{array}$ & $\begin{array}{c}\text { Friability* } \\
\mathbf{( \% )}\end{array}$ & $\begin{array}{c}\text { Disintegration* } \\
\text { Time (Sec) }\end{array}$ & $\begin{array}{c}\text { Wetting* } \\
\text { Time (Sec) }\end{array}$ \\
\hline F1 & 298.68 & 4.2 & 4.12 & $0.718 \pm 0.02$ & $76 \pm 2.00$ & $90 \pm 1.50$ \\
F2 & 295.90 & 3.9 & 3.94 & $0.587 \pm 0.00$ & $42 \pm 0.60$ & $52 \pm 1.30$ \\
F3 & 299.25 & 3.8 & 4.15 & $0.591 \pm 0.02$ & $67 \pm 1.50$ & $58 \pm 1.50$ \\
F4 & 300.20 & 4.1 & 4.10 & $0.782 \pm 0.01$ & $56 \pm 0.30$ & $69 \pm 0.83$ \\
F5 & 298.50 & 3.9 & 4.25 & $0.769 \pm 0.02$ & $49 \pm 2.00$ & $61 \pm 1.50$ \\
F6 & 299.55 & 5.0 & 4.16 & $0.642 \pm 0.01$ & Up to hrs & No much wetting \\
\hline
\end{tabular}

Table III. Results of. dispersion time, wetting volume, $\mathrm{pH}$ of tablet solution and water absorption ratio.

\begin{tabular}{ccccc}
\hline Formulation & $\begin{array}{c}\text { Wetting* volume } \\
(\mathbf{m L})\end{array}$ & $\begin{array}{c}\text { Dispersion* } \\
\text { time (Sec) }\end{array}$ & $\begin{array}{c}\text { pH of } \\
\text { Tablet Sol }\end{array}$ & $\begin{array}{c}\text { Water* } \\
\text { absorption ratio }\end{array}$ \\
\hline F1 & $25 \pm 0.50$ & $68 \pm 1.00$ & 6.8 & $0.90 \pm 0.15$ \\
F2 & $17 \pm 1.50$ & $44 \pm 1.15$ & 6.7 & $1.30 \pm 0.20$ \\
F3 & $24 \pm 0.50$ & $61 \pm 1.00$ & 7.3 & $1.00 \pm 0.10$ \\
F4 & $22 \pm 1.50$ & $57 \pm 1.53$ & 6.8 & $1.10 \pm 0.03$ \\
F5 & $20 \pm 0.50$ & $51 \pm 1.00$ & 6.6 & $1.20 \pm 0.10$ \\
F6 & No such absorption & Up to hrs & 7.3 & No such absorption \\
\hline
\end{tabular}

Table IV. Results of angle of repose, bulk density, tapped density, hausner's ratio and carr's index.

\begin{tabular}{cccccc}
\hline Code & $\begin{array}{c}\text { Bulk Density } \\
(\mathbf{g} / \mathbf{m L})\end{array}$ & $\begin{array}{c}\text { Tapped Density } \\
(\mathbf{g} / \mathbf{m L})\end{array}$ & $\begin{array}{c}\text { Angle of Repose } \\
(\boldsymbol{\theta})\end{array}$ & Hausner's Ratio & $\begin{array}{c}\text { Carr's Index } \\
\mathbf{\%}\end{array}$ \\
\hline F1 & 0.623 & 0.749 & 22.5 & 1.20 & 18.35 \\
F2 & 0.613 & 0.729 & 21.6 & 1.18 & 19.50 \\
F3 & 0.617 & 0.721 & 23.5 & 1.16 & 18.25 \\
F4 & 0.627 & 0.735 & 22.9 & 1.17 & 17.55 \\
F5 & 0.621 & 0.727 & 23.5 & 1.17 & 18.75 \\
F6 & 0.623 & 0.739 & 24.5 & 1.18 & 17.60 \\
\hline
\end{tabular}

physical properties and dissolution tests of G4 formulations tablets with TLM in crystalline and amorphous form after different storage periods were also performed.

Finding of this study are also substantiated by Rao et al. (2011), who reported a simple and rapid reversed phase liquid chromatographic method for separation and determination of the related substances of TLM was developed and validated. he related substances relate to a novel synthetic route and different from those A-H impurities reported by European Pharmacopeia.
Moreover, Zong et al. (2013) reported the solid dispersion systems of TLM with biopolymer carrier chitosan have been investigated in this study. The mechanism of solubilization of chitosan for drug has been studied. In addition, the influence of several factors was carefully examined, including the preparation methods, the drug/carrier weight ratios, and the milling time. Drug dissolution and physical characterization of different binary systems were studied by in vitro dissolution test, particle size distribution, Fourier transform infrared spectroscopy, differential scanning 


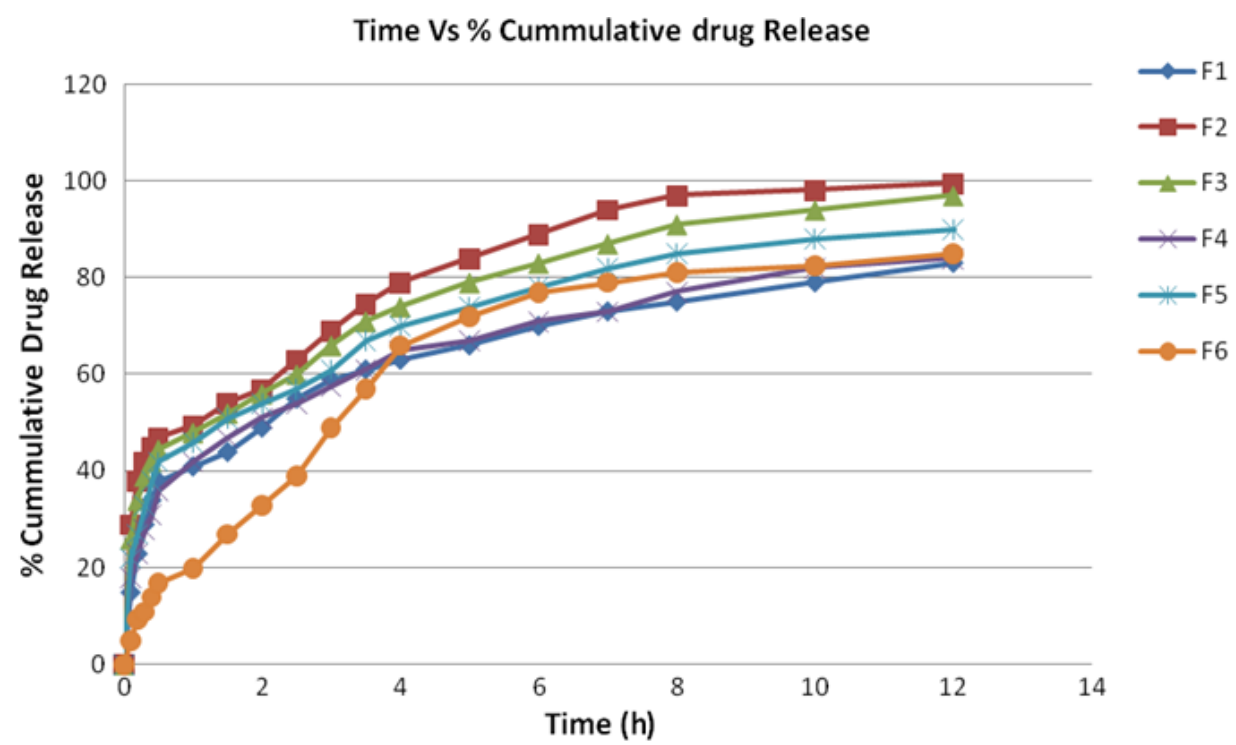

Figure 1. Drug release curves of all 6 formulations upto $12 \mathrm{~h}$.

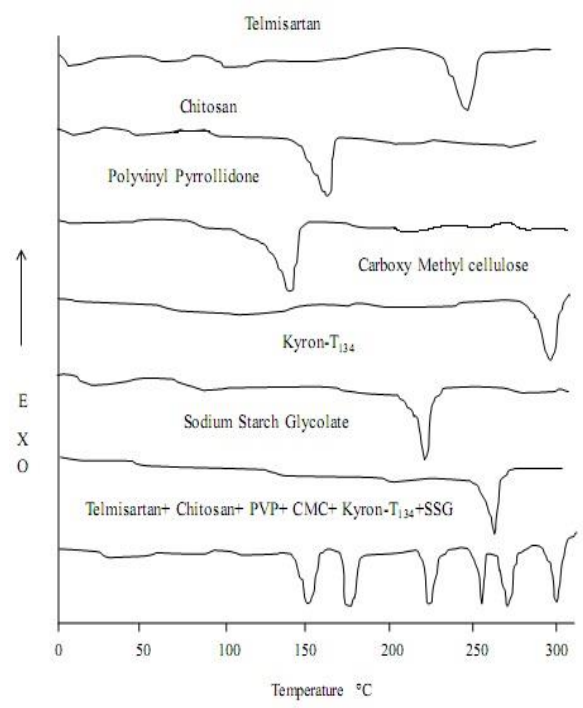

Figure 2. DSC spectra of drug with different excipients.

calorimetry, powder X-ray diffractometry, and scanning electron microscopy. As a result, a significant effect of chitosan increasing TLM dissolution has been demonstrated, and cogrinding in a roll ball mill was the best way to prepare solid dispersions, which had high degree of uniformity in drug content and had a practical application in manufacturing.

Additionally Sekar et al. (2008) reported the TLM as an insoluble in water; hence the drug may be slowly or incompletely dissolved in the gastro intestinal tract. So the rate of dissolution and therefore its bioavailability is less (bioavailability 42\%). In the present study an attempt has been made to prepare immediate release tablets of TLM by using Polyplasdone XL-10 (Crosspovidone) at intragranular, extragranular and partly intra and extragranular level of addition to increase the rate of drug release from dosage form to 


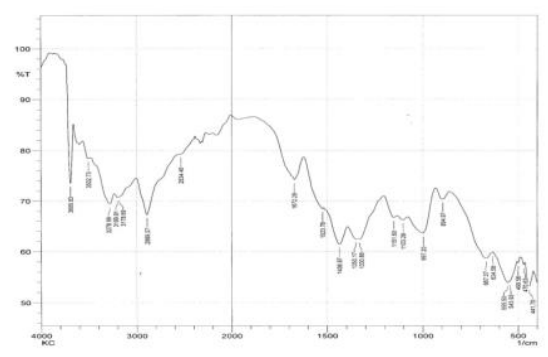

Spectra of Chitosan

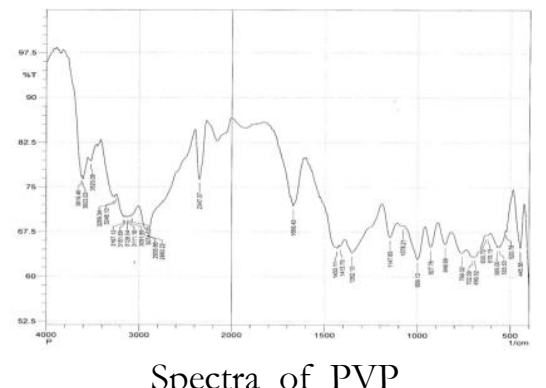

Spectra of PVP
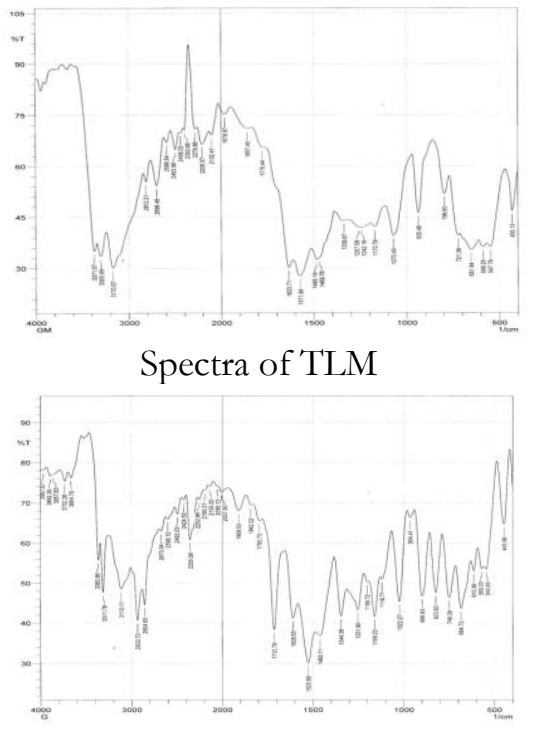

spectra of Primogel
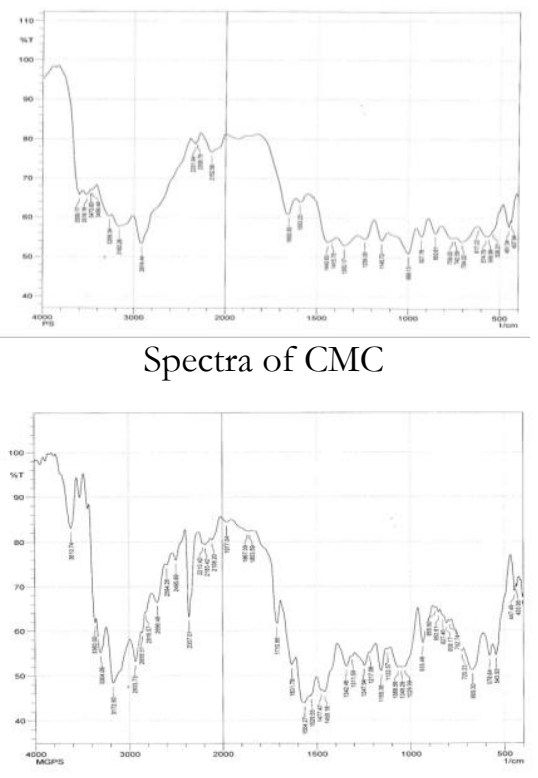

spectra of TLM + chitosan + PVP +

$\mathrm{CMC}$

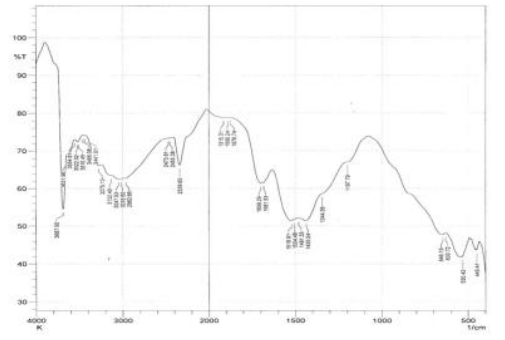

Spectra of Kyron $\mathrm{T}_{134}$

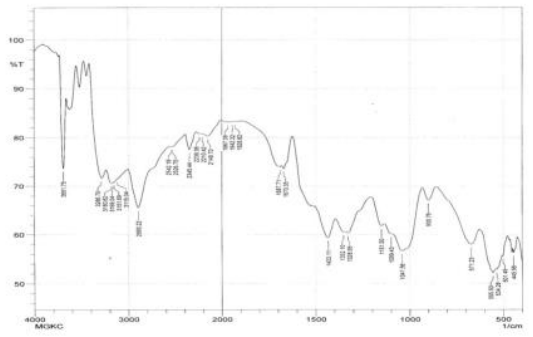

spectra TLM+Kyron $\mathrm{T}_{134}+$ Primogel

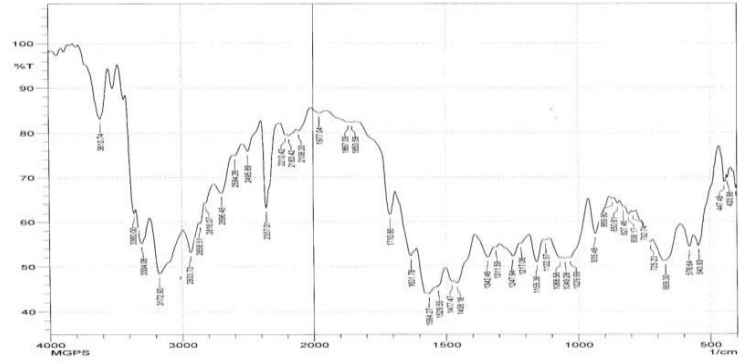

spectra of chitosan +PVP+ CMC+ Kyron T134+ Primogel

Figure 3. FTIR Spectra of TLM, Kyron $\mathrm{T}_{134}$, Primogel, TLM+Kyron $\mathrm{T}_{134}+$ Primogel, Chitosan, CMC, PVP, TLM + chitosan + PVP + CMC and chitosan + PVP+ CMC+ Kyron T134+ Primogel. 
increase the dissolution rate and bioavailability. The prepared granules and tablets were evaluated for their physiochemical properties and in-vitro dissolution study was conducted for the prepared tablets. Moreover, the immediate release tablets with proper hardness, disintegration time and with increase rate of dissolution can be made using Polyplasdone XL-10. Formuation-10 (F10) was selected for stability study and the in-vitro dissolution study showed that was no difference in percent of drug released between initial and sixth month sample (Hafeez et al., 2013).

\section{CONCLUSION}

The determinants of MDERTS can be adjusted with the acceptable range to improve the biological efficiency. DSC and FTIR spectroscopic studies indicate the compatibility of drugs with each other and with excipients. Moreover, the formulation F2 containing more than $10 \%$ of Kyron $\mathrm{T}$ had shown best results. Whereas, the overall results had shown that Kyron $\mathrm{T}$ containing tablets had best, in vitro dispersion time, wetting time and wetting volume, water absorption ratio. In addition of that the rheological properties of blend powder are modifiable and improvable to meet the quality standard specifications for MDERTS. The order in which superdisintegrants and polymers had produced desirable effect is Kyron T134 > Kyron T134134 + primogel > primogel and for polymers chitosan $>$ chitosan+CMC $>$ chitosan + PVP> CMC> $\mathrm{CMC}+\mathrm{PVP}>\mathrm{PVP}$. Thus, Kyron $\mathrm{T}$ is the best superdisintegrant of others which were used in present study and direct compression method is the best used to prepare extended release mouth disintegrating tablets.

\section{ACKNOWLEDGMENT}

Author acknowledgment to Prof. Dr. Nadeem Irfan Bukhari, UCP, University of the Punjab, Lahore, Pakistan, Willson Pharmaceuticals, I-9 Industrial Area Islamabad, Pakistan, Welcare Pharmaceutical, A/7 P.S.I.E. Sargodha, Pakistan.

\section{REFERENCES}

Allen LV Jr. Remington. 2012. The Science and Practice of Pharmacy: from the past into the future. Int J Pharm Compd. 16 (5): $358-62$.

Bankars.K, Chaudhari A.V, Mahale N.B and Chaudhari S.R. 2014. A Review On Orodispersible Tabletsprepared Using Spray Dried Sustained Release Microparticles. Journal of Advanced Drug Delivery. 1(2): 82-95.

Belal TS, Mahrous MS, Abdel-Khalek MM, Daabees HG, Khamis MM. 2014. Validated spectrofluorimetric determination of two pharmaceutical antihypertensive mixtures containing amlodipine besylate together with either candesartan cilexetil or telmisartan. Luminescence. 29(7): 893-900. doi: 10.1002/bio.2638

Hafez HM, Elshanawane AA, Abdelaziz LM, Kamal MM. Quantitative Determination of three Angiotensin-II-receptor Antagonists in Presence of Hydrochlorothiazide by RP-HPLC in their Tablet Preparations. Iran J Pharm Res. 12(4): 635-43.

Ieva E, Trapani A, Cioffi N, Ditaranto N, Monopoli A, Sabbatini L. 2009. Analytical characterization of chitosan nanoparticles for peptide drug delivery applications. Anal Bioanal Chem. 393(1): 207-15. doi: 10.1007/s00216-008-2463-4

Lepek P, Sawicki W, Wlodarski K, Wojnarowska Z, Paluch M, Guzik L. 2013. Effect of amorphization method on TLM solubility and the tableting process. Eur J Pharm Biopharm. 83(1):114-21. doi: 10.1016/j.ejpb.2012.09.019. PubMed PMID: 23085331.

Rao RN, Guru Prasad K, Gangu Naidu Ch, Maurya PK. 2011. Development of a validated liquid chromatographic method for determination of related substances of TLM in bulk drugs and formulations. J Pharm Biomed Anal. 56(3): 471-8. doi: 10.1016/j.jpba.2011.05.043. PubMed PMID: 21719227.

Ravi Kumar MNV, Muzzarelli RAA, Muzzarelli C, Sashiwa H, Domb AJ. 2004. Chitosan Chemistry and Pharmaceutical Perspectives. Chem. Rev. 104: 60176084. 
Sekar V, Chellan VR. 2008. Immediate release tablets of TLM using superdisintegrantformulation, evaluation and stability studies. Chem Pharm Bull (Tokyo). 56(4): 575-7. PubMed PMID: 18379110.

Shanmugam S. 2015. Granulation techniques and technologies: recent progresses. Bioimpacts. 2015;5(1): 55-63. doi: 10.15171/bi.2015.04
Zhong L, Zhu X, Luo X, Su W. 2013. Dissolution properties and physical characterization of TLM-chitosan solid dispersions prepared by mechanochemical activation. AAPS PharmSciTech. 14(2): 541-50. doi: 10.1208/s12249-013-9937-1. PubMed PMID: 23430728; PubMed Central PMCID: PMC3665993. 